\title{
Large sulfur isotope fractionation in lunar volcanic glasses reveals the magmatic differentiation and degassing of the Moon
}

\author{
ALBERTO SAAL ${ }^{1}$ AND ERIK HAURI ${ }^{2}$ \\ ${ }^{1}$ Brown University \\ ${ }^{2}$ Carnegie Institution for Science \\ Presenting Author: asaal@brown.edu
}

Sulfur isotope variations in mantle-derived lavas provide important constraints on the evolution of planetary bodies. Here, we report the first in situ NanoSIMS measurements of sulfur isotope ratios dissolved in primitive volcanic glasses and olivinehosted melt inclusions recovered from the Moon by the Apollo missions. These samples represent some of the best-studied and most primitive magmas generated from within the deepest regions of Moon. The measured $\delta^{34} \mathrm{~S}$ value $\left(\delta^{34} \mathrm{~S}=\right.$ $\left.\left[\left({ }^{34} \mathrm{~S} /{ }^{32} \mathrm{~S}\right)_{\text {sample }} /\left({ }^{34} \mathrm{~S} /{ }^{32} \mathrm{~S}\right)_{\mathrm{V}-\mathrm{CDT}}-1\right] \times 1000\right)$ of the volcanic glass beads provides the isotopic composition of the magma at the time of fragmentation and eruption, before any interaction with the regolith and deposition of any surface coating. We examined three compositional groups: the very low- and low-Ti glasses from Apollo 15 (15426 and 15427) and the high-Ti glasses from Apollo 17 (74220). The $\delta^{34} \mathrm{~S}$ values vary from +1.3 to $-1.8 \%$ o in the high-Ti glasses, with their melt inclusions ranging from +1.6 to $-0.30 \%$, whereas the $\delta^{34} \mathrm{~S}$ values of low- and very low-Ti glasses vary from -0.27 to $-4.70 \%$ and from -4.80 to $-14 \%$, respectively. The new data reveal large variations in $\delta^{34} \mathrm{~S}$, which define positive correlations with the sulfur and other volatile element contents within each compositional group and with the sulfur and titanium contents among the different groups of volcanic glasses analyzed. Our results uncover several magmatic events that fractionated the primordial sulfur isotope composition of the Moon: Magma degassing during generation, transport, and eruption of the lunar lavas is responsible for the large variations in $\delta^{34} \mathrm{~S}$ within each compositional group. Once magmatic degassing is accounted for, the variations in $\delta^{34} S$ among the different compositional groups can be explained by the segregation of the lunar core and the crystallization of the lunar magma ocean, which led to the formation of the heterogeneous sources of the lunar magmatism. Whether the Earth's and Moon's interiors share a common ${ }^{34} \mathrm{~S} /{ }^{32} \mathrm{~S}$ ratio remains a matter of debate. 